\title{
Optimization of laser welding of dissimilar corrosion resistant alloys
}

\author{
Michele Cavallini, Paolo Veronesi, Luca Lusvarghi, \\ Elenca Colombini, Roberto Giovanardi \\ Dept of Engineering "'Enzo Ferrari" \\ University of Modena and Reggio Emilia \\ Modena, Italy
}

\author{
Lorenzo Rigon \\ Ecor Research \\ Modena, Italy
}

\begin{abstract}
The use of multi-materials components has the benefit of coupling each material's benefit where it is needed, thus achieving, for instance, heat, wear and corrosion resistance. Joining of dissimilar metals is a challenging task due to the large differences in properties. In this framework, the use of (Quasi Continuous Wave (QCW) Fiber Lasers) proved to be effective in multi-materials components assembly thanks to the high power density but low energy-input. In this paper the laser welding of dissimilar materials, namely stellite and stainless steel, is investigated and optimized in terms of corrosion resistance, comparing the results to conventional brazing joining. Results demonstrate that the optimized laser welding conditions, with the use of a proper filler material, lead to the obtainment of defectfree joints, with minimum alteration of the base materials.
\end{abstract}

Keywords-laser welding; corrosion resistance, optimization, design of experiments

\section{INTRODUCTION}

Laser has been widely used as a heat source for materials processing, mainly in the field of welding [1] and cladding [24]. When joining dissimilar alloys, laser welding method presents many advantages over more conventional welding techniques (like arc welding), such as high energy density, rapid heating/cooling speed and accessibility to the heating zone [5-6]. Moreover, when adding a filler material, the laser welding-brazing method can help suppressing the growth of brittle intermetallic compounds at the joint site [7-9]. Hence, mechanical properties of the joint obtained by laser weldingbrazing can be enhanced, and the same applies to corrosion resistance.

Stainless steel usually presents a satisfactory corrosion resistance in many environments, but they tend to suffer from poor surface hardness, which can result detrimental when wear resistance is required. In order to overcome this limit, both diffusive processes, like kolsterizing of austenitic stainless steels [10] or cladding with more wear resistance alloys [11] have been used. Sainless steel can be subjected to sensibilization a process that, due to the formation of chromium carbides, leads to local depletion of chromium, leading to loss of corrosion resistance. Hence, when welding such materials with carbon-richer ones, this phenomenon could occur, with detrimental effects on the part lifespan. However, sometimes the product requirement should be not suitable surface treatment can be done and the use of dissimilar materials in the same component is mandatory. Stellite is the commercial name of cobalt-chromium alloys, invented in 1906. Chromium plays a dual role of solid solution strengthening of the cobalt matrix and of carbide former, together with additions of tungsten, depending on the stellite type. Carbon, manganese and molybdenum can be present as well in the alloy. Chromium imparts a further corrosion resistance, but care must be taken in order to avoid possible presence of $\mathrm{Ni}$ and $\mathrm{Fe}$ in the alloy, as it decreases both mechanical and chemical resistance properties, for quantities higher than 3\% [12]. When joining by welding stellite to stainless steels, dilution can occur, locally reaching such high level of Fe and Ni content. Stellite cladding on stainless steels is usually performed by locally melting the stellite directly on the component surface by PTAW (Plasma Transferred Arc Welding), GTAW (Gas Tungsten Arc Welding) or even TIG (Tungsten Inert Gas Welding). During cladding the processing parameters are set so that only the cladding material is molten, trying to avoid possible dilution. Cladding is used, as shown in a previous study [13], to have a harder and more wear resistant surface on tools, blades and similar. However, cladding thickness is usually limited and the possibility of having multi-materials part is of interest for these fields of application.

Hence, in this work a different approach, i.e. Quasi Continuous Wave (QCW) Fiber Lasers of stellite to AISI420 stainless steel is investigated, as a promising technique to fabricate multi-materials parts and retaining the good wear and corrosion resistance properties of each one of the base materials.

\section{MATERIALS AND METHODS}

\section{A. Materials}

Stellite $6 \mathrm{k}$ and hardened AISI420 stainless steel plates have been used in this study. Stellite $6 \mathrm{k}$ is obtained by powder metallurgy methods, and the $6 \mathrm{k}$ variety has been selected in this study due to its relatively low carbon content, which is expected to prevent sensibilization of AISI 420 steel. The latter is in the heat treated (hardened) condition, simulating real requirements of this multi-material part, i.e. high mechanical properties and good corrosion resistance. Table I shows the chemical analysis of the investigated materials. 
TABLE I. COMPOSITION OF THE BASE MATERIALS

\begin{tabular}{|l|c|c|}
\hline & Stellite 6k & AISI 420 \\
\hline $\mathrm{Co}$ & bal & 13 \\
\hline $\mathrm{Cr}$ & 31.9 & bal \\
\hline $\mathrm{Fe}$ & 2 & \\
\hline $\mathrm{Ni}$ & 2 & 0.5 \\
\hline $\mathrm{Mo}$ & 1.5 & 0.85 \\
\hline $\mathrm{Si}$ & 1 & \\
\hline $\mathrm{Mn}$ & 1 & $<0.15$ \\
\hline $\mathrm{W}$ & 4 & \multicolumn{2}{|c|}{} \\
\hline $\mathrm{C}$ & 1.6 & \\
\hline
\end{tabular}

\section{B. Joining process}

Joining of dissimilar materials was performed using a Fiber Ytterbium (Yag) laser source which emits light with a wavelength of $1064 \mu \mathrm{m}$, kindly supplied for testing purposes by Sisma, model Sisma SWA150.Due to the high number od parameters and their interdependence, simple trials and error method was exploited to contain the test number, thus several samples were welded and analyzed to find out the optimal set parameters and the most suitable set parameter was defined. The parameters set are: average power of $150 \mathrm{~W}$, peak power up to $10,5 \mathrm{~kW}$, pulse energy up to $70 \mathrm{~J}$, pulse duration $6.8 \mathrm{~ms}$, spot size $1 \mathrm{~mm}$, frequency $8 \mathrm{~Hz}$. Both direct joining with no filler material and with filler material have been tested, varying the laser source parameters in order to optimize the joint quality, evaluated by Scanning electron microscopy (SEM) and image analysis on polished and etched cross sections and by microhardness measurements. When no filler material was used, the base materials have been preheated at $350^{\circ} \mathrm{C}$, while for laser brazing tests, two different filler materials (one Febased, i.e. AISI 316L and one Ni-based, i.e. modified Inconel $625)$ have been tested. Brazing in inert atmosphere in furnace at $1020^{\circ} \mathrm{C}$ for 20 minutes was tested as well, using Ni-based Nicrobraz L.M ally as filler, for the comparison's sake.

\section{Corrosion resistance}

Polarization tests have been conducted on welded zones using a 3-electrodes cell (K0235 Flat Cell, Princeton Applied Research, Oak Ridge, Tennessee, USA), which allows to test $100 \mathrm{~mm} 2$ of surface. Due to the not perfectly planar nature of the sample, a PTFE mask has been used, in order to expose only the area under testing and have it immersed in the testing solution. One electrode is the sample itself, while at the other end of the cell, a Pt grid is used as counter electrode, in presence of a third reference electrode of the $\mathrm{Ag} / \mathrm{AgCl} / \mathrm{KCl}$ (sat.) type. Samples have been carefully cleaned in acetone prior to testing, which was conducted using an Ametek VersaStat3 (Princeton Applied Research) potentiostat, first measuring the OCP - Open Circuit Potential (i.e, the potential with respect to the reference electrode, starting from $-0.4 \mathrm{~V}$ to $1.6 \mathrm{~V}$. By measuring the current passing through the described circuit, a polarization curve is obtained, which serves to assess the corrosion resistance in a reference environment. In this study a saline solution $\mathrm{NaCl}(3 \mathrm{wt} \%)$ and the same solution with $0.1 \mathrm{M}$ citric acid solution have been used.

\section{RESULTS AND DISCUSSION}

Brazing results in inert atmosphere in furnace are shown in figure 1, where a SEM micrograph of the interface is investigated. Large hard and brittle phases are present (dark areas), indicating that possible carbide formation occurred. Hardness measurements on the base materials near the fused zone of the brazing showed that stellite is almost unaffected, with $480 \pm 10 \mathrm{HV} 1$, while on the stainless steel side, a significant drop down to $290 \pm 10 \mathrm{HV} 1$ is encountered, compared to a starting average hardness of $520 \mathrm{HV} 1$. This is expected, due to the high brazing temperature, which lead to tempering of the quenched steel.

Given these premises, a set of experiments with no filler material, using laser welding has been performed. In all cases, even varying laser power, pulse duration and spot size, the welding region, even if small sized, is severely cracked, due to an excessive mismatch of thermal and mechanical properties of the two base materials. Hence, brazing, as expected, could represent a promising tradeoff between satisfactory joint properties and minimum alteration of the nearby base materials. When using AISI316L wire, $0.7 \mathrm{~mm}$ diameter, as filler material, severe cracking occurred on the samples surface in the fused zone (Figure 2), and lack of penetration of the welding was encountered in all cases, indicating a not high enough energy input from the source.

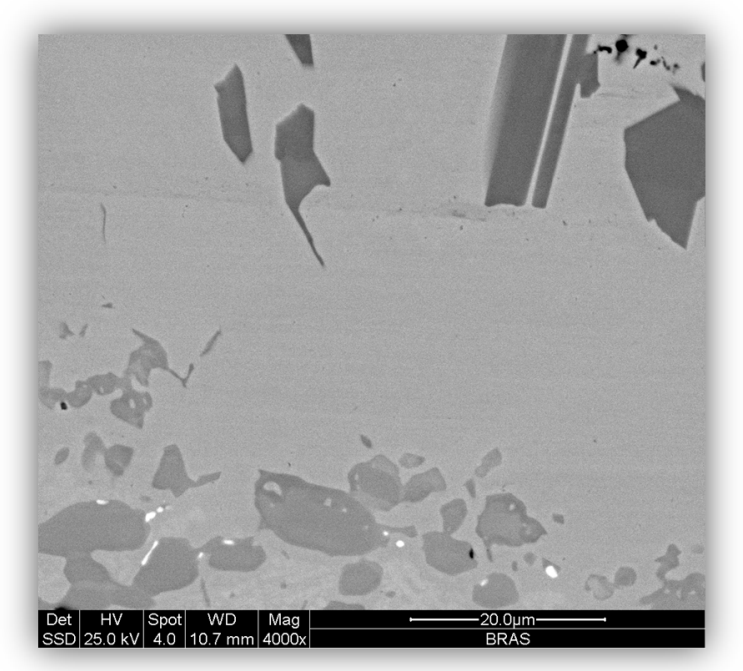

Fig. 1. SEM micrograph (BSE) of the interface obtained by brazing 


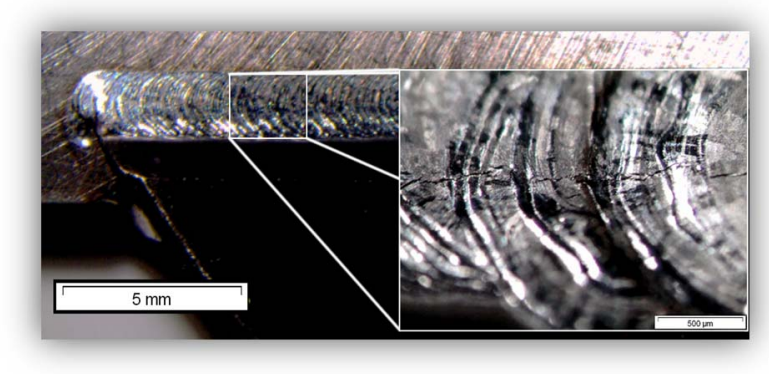

Fig. 2. Surface of laser brazed sample, AISI316L filler material, showing cracks

Due to the promising results of Ni-based laser brazing the optimization of the process was conducted, exploiting as optimization term both the melted extension and the penetration depth of welding.

Figure 3 shows an example of the cross section of a good laser brazing, with almost complete penetration.

The laser brazing parameters investigated have been the source power (as percentage of the maximum output power available) and the pulse duration, for a given filler wire diameter $(0.75 \mathrm{~mm})$. Results present a high variance, due to the fact that during tests the laser brazing was conducted manually (i.e. not automated). Moreover, as brazing proceeds from the start to the end, boundary conditions (temperature of base material, extension of the base material zones acting as heat sinks) change, hence depending on the position of the cross section a strong variability occurs also within the same set of parameters. Nevertheless starting from experimental result, a statistical trend has been found, as shown in Figure 4 and 5, where the axis values are expressed as percentage of a reference value.

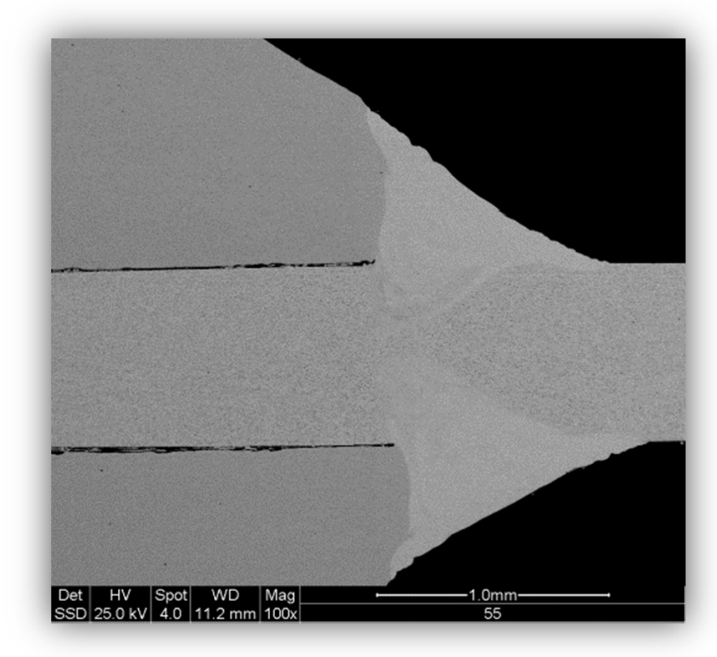

Fig. 3. Proper brazing geometry (cross section), with large enough fused area and good penetration

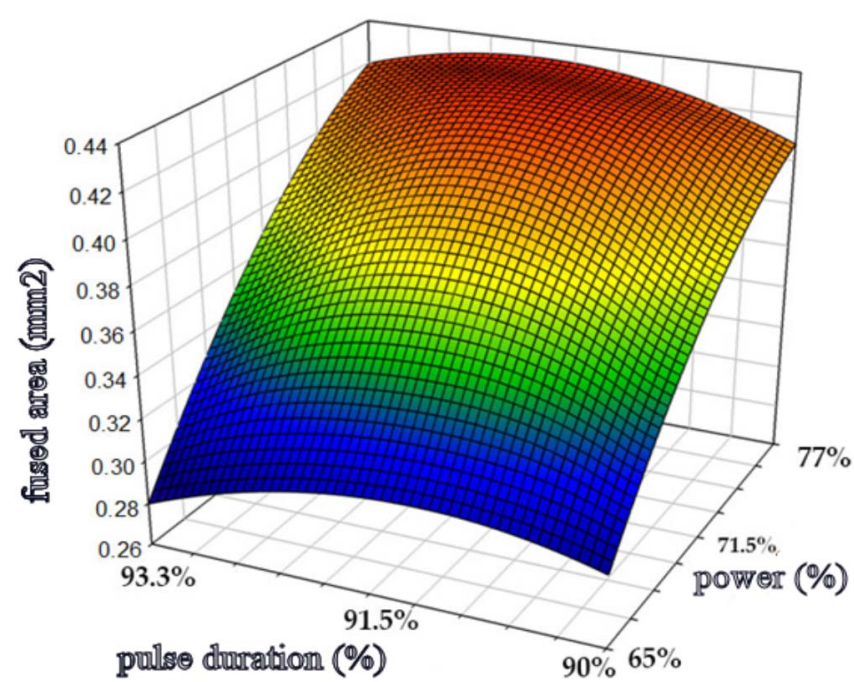

Fig. 4. Fused area extension as a function of pulse duration and laser power

The two responses have a simlar trend, as both depend on the heat input; hence, maximizing penetration involves also the maximization of the fused area extension, and this is not necessarily required, as it can lead to excessive penetration and dilution of the base materials. Laser power seems to be a more relevant factor in the investigated experimental space, while the pulse duration has a minimum effect on the extension of the fused area and penetration. However, when plotting the examined responses as a function of the heat input, it is evident that there is a kind of transition between two different behaviours, from 12 to $13 \mathrm{~J}$, as shown in figures 6 and 7, where heat is the value provided by laser, which also evaluates the disperison inside the laser itself. This non linear behaviour can be ascribed to the complexity of phenomena involved in laser brazing, including the change of properties (both thermal and optical) as a function of temperature. 


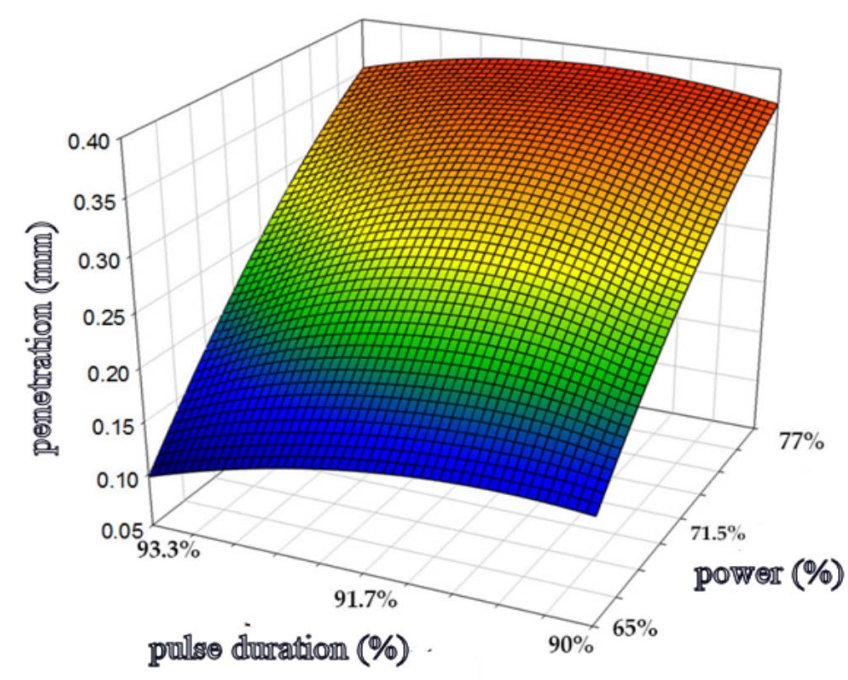

Fig. 5. Penetration as a function of pulse duration and laser power

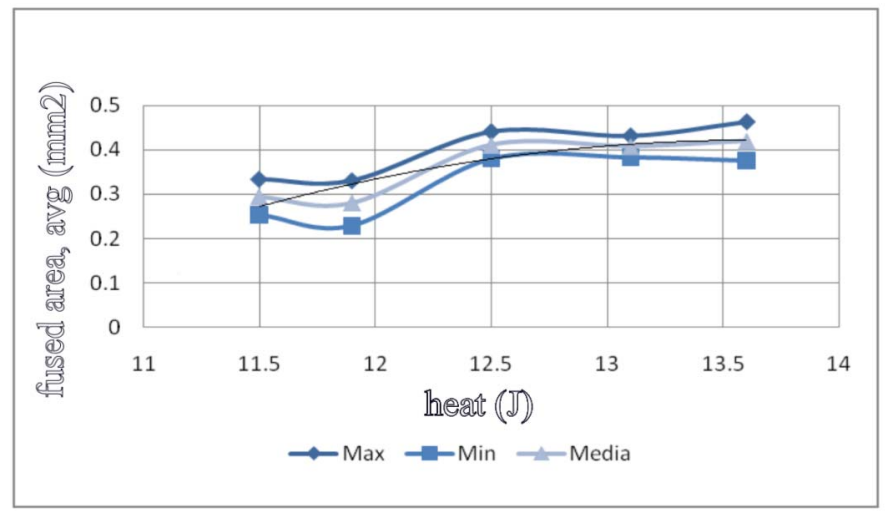

Fig. 6. Fused area extension as a function of heat input

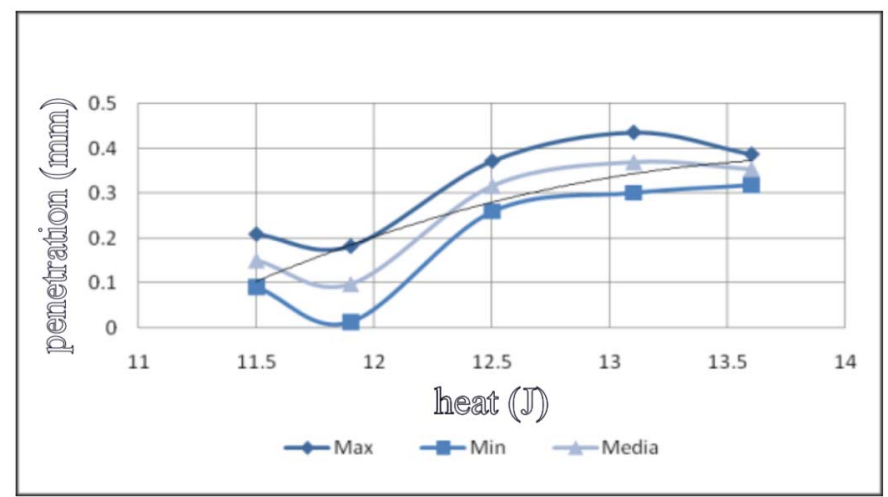

Fig. 7. Penetration as a function of heat input

Optimization based on the correlation graphs allowed to identify a set of parameters able to guarantee a proper penetration without extending excessively the fused area, roughly corresponding to an heat outout of $12.5 \mathrm{~J}$. Figure 8 shows the results obtained on repeated samples with the same set of optimized parameters. As previously mentioned, there is a strong variability within the same sample (set of parameters), and this is evident considering the presence of porosity (round shaped, large, in two out of 12 cross sections) and of different concavity of the fused zone.

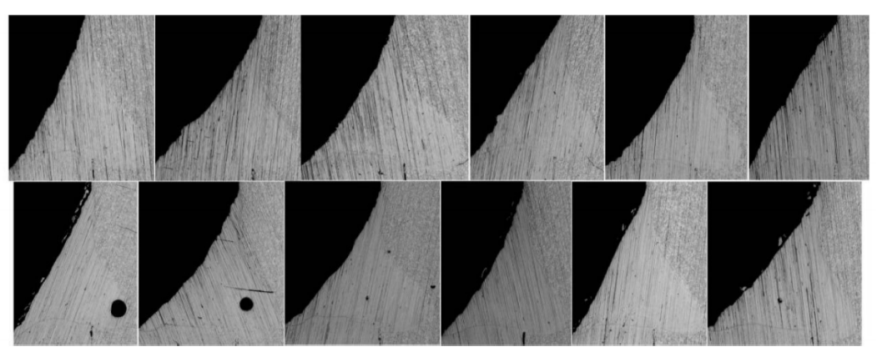

Fig. 8. Optical micrographs of the cross sections of samples laser brazed in optimized conditions, focussed on the fused zone

SEM-EDS analyses on the fused zone show that mixing occurred at the apex of the fused zone, as shown in figure 9. Darker areas are Fe-richer, lighter ones are Ni-richer. The regions at the apex are darker, as they are nearer the substrates, and hence $\mathrm{Fe}$ and $\mathrm{Co}$ richer. This indicates that the base materials have been melted, as expected, and hence good metallurgical bond is achieved. However, these regions are quite heterogeneous, indicating that homogenization did not take place, due to the extremely rapid cooling which is associated with the laser welding parameters used.

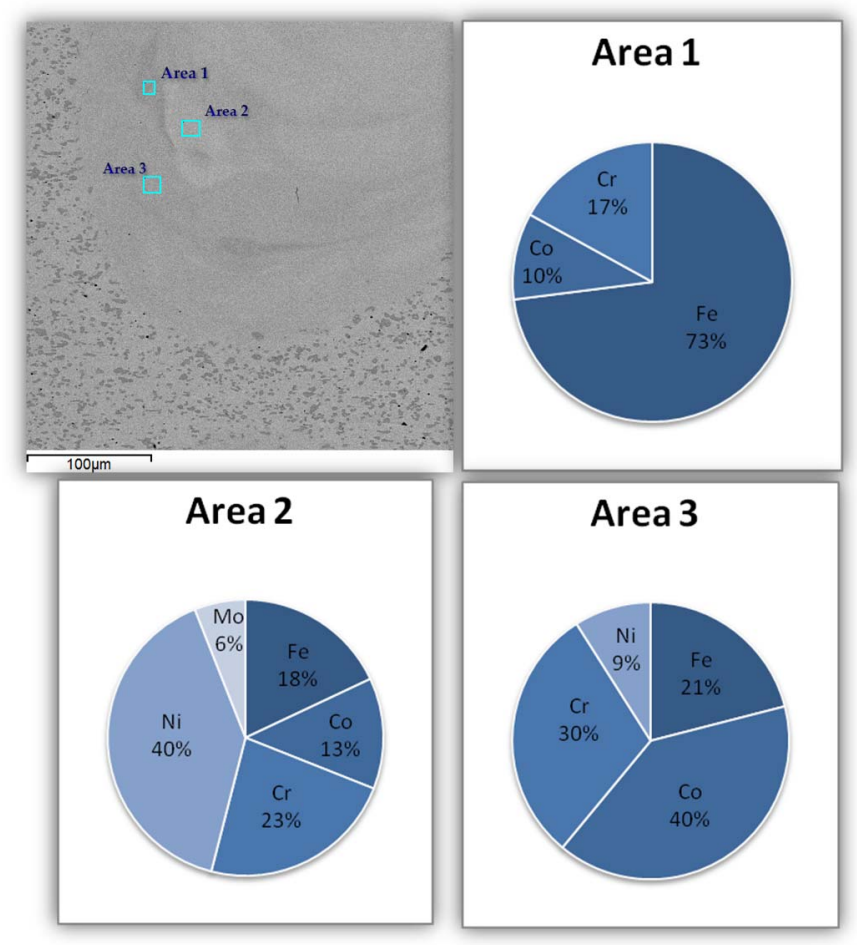

Fig. 9. SEM micrograph and semi-quantitative EDS analyses on neighboring regions at the fused zone apex

Microscopic examination confirms the good quality of the optimized joints, also retaining the hardness of the base material, due to the very limited extension of the heat affected zones. However the large heat input used during brazing is 
expected to have detrimental effects on the corrosion resistance of the joint and of the heat affected zones of the base materials. Polarization tests have been conducted with the aim to verify possible loss of corrosion resistance in the most common environments, simulated by $\mathrm{NaCl}$ and citric acid solutions. Results indicate that one of the base materials, AISI420, is already not enough corrosion resistant in the demanding testing environment, hence the joint is expected to inherit such behavior. A possible solution could be the application of a protective coating, which would protect also the laser brazed region. A $2 \mu \mathrm{m}$ thick $\mathrm{CrN}$ coating deposited by PVD was tested, as it is one of the most common used coatings for such materials, but the results, shown in Figure 10, demonstrate that it is not effective in preventing corrosion. Hence a better coating has to be used, presenting no open porosities and a better corrosion resistance. This is the aim of the current studies.

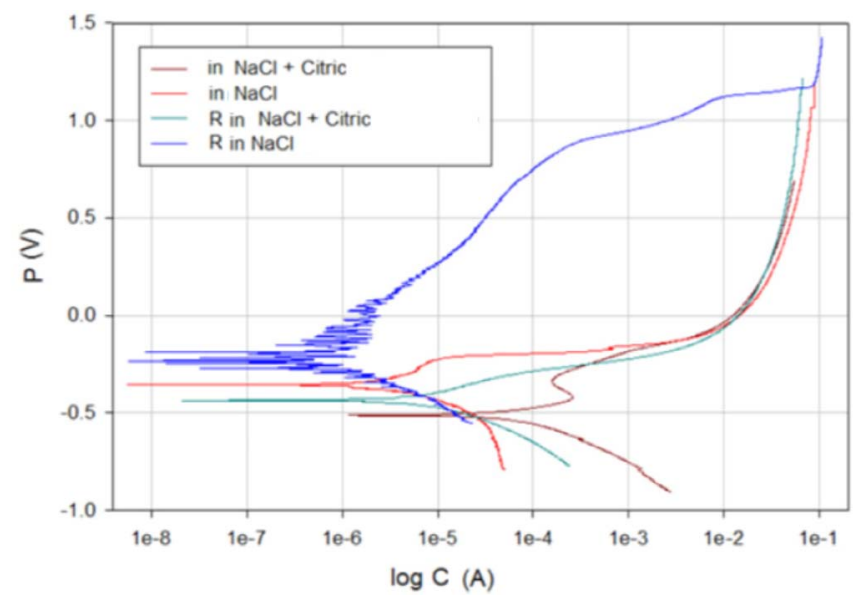

Fig. 10. Polarization curves (Potential vs log current) of AISI420, without and with ( $\mathrm{R}$ prefix) $\mathrm{CrN}$ coating

\section{CONCLUSIONS}

Laser brazing with Ni-based filler material allowed to obtain multi-material parts made of AISI 420 stainless steel and Stellite 6. Optimization of the brazing parameters allowed to find suitable tradeoffs between the penetration and the extension of the fused area. Due to the manual operations involved in the tests, a strong variability within samples has been recorded, which could be decreased moving towards automated welding procedures. Compared to welding, the base materials properties are almost unaffected, and no formation of brittle intermetallics or carbides is evident in the examined cross sections. Corrosion resistance of one of the base materials (AISI 420) in concentrated $\mathrm{NaCl}$ solution is not satisfactory and it was not possible to achieve improvements applying a thin $\mathrm{CrN}$ coating. However the use of possible alternative coatings could improve the corrosion resistance, extending the benefits also to the welded zone.

\section{REFERENCES}

[1] H.S. Wang, H.G. Chen, J.S.C. Jang, J. Alloys Compd., 495 (2010), pp. 224-228.

[2] H. Yan, A.H. Wang, K.D. Xu, W.Y. Wang, Z.W. Huang, J. Alloys Compd., 505 (2010), pp. 645-653.

[3] C.G. Li, Y. Wang, L.X. Guo, J.Q. He, Z.Y. Pan, L. Wang, J. Alloys Compd., 506 (2010), pp. 356-363.

[4] X.B. Liu, G. Yu, J. Guo, Y.J. Gu, M. Pang, C.Y. Zheng, H.H. Wang, J. Alloys Compd., 453 (2008), pp. 371-378.

[5] X.B. Liu, M. Pang, J. Guo, G. Yu, J. Alloys Compd., 461 (2008), pp. 648-653.

[6] H. Laukant, C. Wallmann, M. Korte, U. Glatzel, Adv. Mater. Res., 6-8 (2005), pp. 163-170

[7] K. Saida, W. Song, K. Nishimoto, Sci. Technol. Weld. Joint, 10 (2005), pp. 227-235.

[8] R. Borrsutthekul, T. Yachi, Y. Miyashita, Y. Mutoh, Mater. Sci. Eng. A, 467 (2007), pp. 108-113.

[9] G. Sierra, P. Peyre, F. Deschaux Beaume, D. Stuart, G. Fras, Mater. Charact., 59 (2010), pp. 1705-1715.

[10] R.H.Van Der Hagt, Heat Treatment of Metals 27(3) (2000), pp. 62-65 .

[11] A. Tiziani, L. Giordano, P. Matteazzi, B. Badan, Mater. Sci. ENg. , 88 (1987), pp. 171-175.

[12] Stellite, D.: Guidelines for hardfacing onto steels. In: http://www.stellite.co.uk/Portals/0/Guidelines\%20for\%20hardfacing\%2 0onto\%20steels.pdf. (Accessed April 22, 2017) Available at: http://www.stellite.co.uk/Portals/0/Guidelines\%20for\%20hardfacing\%2 0onto\%20steels.pdf

[13] X Shen, W. Teng, S. Zhao, W. HE, Physics Procedia 83 (2016), pp.406416. 